\title{
HDL Particle Size Measurement
}

National Cancer Institute

\section{Source}

National Cancer Institute. HDL Particle Size Measurement. NCI Thesaurus. Code C103402.

The determination of the amount of the average particle size of high-density lipoprotein in a sample. 